\title{
Inhibition of chemotaxis by organic acids from anaerobes may prevent a purulent response in bacterial vaginosis
}

\author{
S. AL-MUSHRIF, A. ELEY and B. M. JONES \\ Division of Molecular and Genetic Medicine, University of Sheffield Medical School, Sheffield, S10 2RX
}

\begin{abstract}
It has been postulated that certain organic acids produced by the anaerobes associated with bacterial vaginosis (BV) could prevent a purulent response in this infection. Varying concentrations of pure succinic, acetic and lactic acids were incubated in vitro with a monocytic cell line (MonoMac 6). High inhibition of chemotaxis was produced by succinic acid; lower inhibition and no inhibition was shown by acetic acid and lactic acid respectively. Succinic and acetic acids were detected in high concentrations in the vaginal fluid of women with BV and in culture supernates of Prevotella and Mobiluncus spp.; these acids impaired chemotaxis of MonoMac 6 cells in vitro. The vaginal fluids of normal women and the culture supernates of Lactobacillus spp. had no effect on chemotaxis.
\end{abstract}

\section{Introduction}

In 1955, Gardner and Dukes [1] described the distinct clinical entity of bacterial vaginosis (BV). The major symptoms are vaginal malodour and increased discharge, but inflammation of the vaginal wall or other irritative symptoms are uncommon. Furthermore, there is usually a complete lack of polymorphonuclear leucocytes (PMNL; 'pus' cells), which is unusual in such a massive infection. The pathogenesis of BV and the role of the mixture of invading organisms, which includes Gardnerella vaginalis, Prevotella and Mobiluncus spp., is poorly understood [2, 3]. The additional presence of peptococci, peptostreptococci, Ureaplasma and Mycoplasma spp. adds to the complexity.

The initial response of the body to invasion by pathogenic micro-organisms and the events in the first few hours are critical in determining the outcome of infection. Neutrophil PMNLs play an important role in this early response, because one of their functions is directing migration toward a specific location in the body, a phenomenon called chemotaxis. Chemotaxis follows the recognition by the neutrophil of chemical substances (chemotactic factors) and ensures that leucocytes accumulate where they are needed. Subsequent phagocytosis forms a first line of defence.

Received 24 Nov. 1999; revised version accepted 6 April 2000.

Corresponding author: Dr A. Eley.
Chemokines are a superfamily of chemotactic cytokines with $>20$ recognised members. They are highly conserved, basic, $8-10-\mathrm{kDa}$ proteins with a characteristic four-cysteine motif within amino acid sequences [4]. Chemokines are produced by several cell types and injured tissues, besides leucocytes, including haematopoietic cells, endothelial cells, fibroblasts, tumour cells, neuronal cells and primordial cells [5]. Cytokines are now known to be chemotactic agents that act on all types of leucocytes. They stimulate endothelial cells to produce soluble inflammatory mediators, such as interleukin-1 (IL-1) and monocyte chemotactic protein-1 (MCP-1). Complement-5 as a chemoattractant and as an anaphylatoxin is the most active and probably the most biologically important of the complement-derived chemotactic factors.

Inhibition of chemotaxis might be an important virulence factor in the early stages of $\mathrm{BV}$, where neutrophil chemotaxis could be inhibited by some of the associated organisms. It has been suggested that anaerobes are symbiotically associated in mixed infections with aerobic bacteria and could play a key role in their pathogenicity, as their elimination by prophylactic anti-anaerobe chemotherapy (e.g., metronidazole) can prevent the establishment of aerobic infection [6]. Many authors have demonstrated that anaerobes can act synergically with aerobes [7] to increase the virulence of infection in several experimental animal models [8, 9].

Mackowiak [10] suggested four possible mechanisms 
by which one bacterial partner acts in a mixed infection such as (1) its effect on host defences, e.g., inhibition of leucocyte function, (2) provision of essential nutrients, (3) improvement of the local environment, and (4) increased virulence of the organisms.

Potential virulence factors of Prevotella spp. previously investigated include bacterial capsulation [11], the production of tissue toxic enzymes, e.g., fibrinolysins and collagenases [12], and elaboration of soluble factors that alter PMNL function [13]. Several Prevotella species produce a low-mol. wt $(<500 \mathrm{Da})$, heat-stable factor that irreversibly impairs PMNL chemotactic migration.

Volatile fatty acids (VFA) have interesting biological effects on eukaryotic cells, inducing alterations of cell shape, morphological differentiation, changes in the composition of the cytoplasmic membrane and growth inhibition. Short-chain VFA are produced and released extracellularly in high amounts by anaerobic bacteria. Succinic acid (non-volatile, four-carbon dicarboxylic fatty acid) is produced by some BV-associated organisms and has been shown to inhibit several PMNL functions, including phagocytic killing of Escherichia coli and chemotaxis [14].

The aims of this study were to identify potential virulence factors that alter the chemotactic response of a MonoMac 6 cell line and human monocytes. These were considered to be organic acids produced by BV-associated organisms, which, as potential candidates for anti-chemotactic agents, might play a role in the pathogenesis of BV. Therefore, the study aimed to examine: the concentration of VFAs and non-volatile fatty acids (NVFAs) produced in broth culture by lactobacilli and the organisms associated with $\mathrm{BV}$; the concentrations of these fatty acids in the vaginal fluid of normal women and those with $\mathrm{BV}$; the inhibition of chemotaxis of MonoMac 6 cells by pure succinic, acetic and lactic acids; the inhibition of chemotaxis by VFA and NVFA generated by lactobacilli and the organisms associated with $\mathrm{BV}$; and the inhibition of chemotaxis by the VFA and NVFA present in the vaginal secretions of normal women and those with BV.

\section{Materials and methods}

\section{Chromatography apparatus}

This was a dual flame-ionisation, gas chromatography apparatus, type PU 4550, coupled to a PU 4811 computing integrator (Philips Analytical, Cambridge). Nitrogen $\left(\mathrm{N}_{2}\right)$ was used as the carrier gas and the flow rate was adjusted to $20 \mathrm{ml} / \mathrm{min}$. Glass columns, $1.5 \mathrm{~m}$ in length, $4 \mathrm{~mm}$ internal diameter, packed with FFAP (free fatty acid phase) stationary phase, were used (Philips Analytical) in addition to a $1-\mu 1$ Grob, splitless injection system.

\section{Volatile and non-volatile fatty acid standards}

Commercially available quantitative standards were obtained from Sulpelco (Dorset). These contained known concentrations of VFAs (acetic, propionic, isobutyric, butyric, isovaleric, valeric, isocaproic, caproic and heptanoic acids) and NVFAs (pyruvic, lactic, oxalacetic, oxalic, methylmalonic, malonic, fumaric and succinic).

\section{Measurement of VFA}

The standard $(0.5-\mathrm{ml}$ volume $)$ was pipetted into a $100 \mathrm{~mm} \times 10 \mathrm{~mm}$ glass tube, this was acidified with $0.1 \mathrm{ml}$ of $\mathrm{H}_{2} \mathrm{SO}_{4} 50 \%$ and $0.5 \mathrm{ml}$ of ethyl ether was added; the tube was stoppered with a silicone bung. The tube was gently inverted 20 times and centrifuged at $1000 \mathrm{~g}$ for $3 \mathrm{~min}$. The upper ether extract was removed carefully into a second tube, which was again stoppered until the sample was tested. Samples $(0.5-\mathrm{ml}$ volumes) of the vaginal secretion suspensions and culture supernates were treated in the same way.

\section{Measurement of NVFA}

The standard $(0.5 \mathrm{ml})$ was pipetted into a $100 \mathrm{~mm} \times 10 \mathrm{~mm}$ glass tube and was acidified with $0.1 \mathrm{ml}$ of $\mathrm{H}_{2} \mathrm{SO}_{4} 50 \%$. Methanol $(1 \mathrm{ml})$ was added; and the tube was stoppered with a silicone rubber bung and mixed and incubated at $56^{\circ} \mathrm{C}$ for $30 \mathrm{~min}$ in a water bath. Distilled water $(0.5 \mathrm{ml})$ and chloroform $(0.5 \mathrm{ml})$ were then added and the tube was inverted gently 20 times. After centrifugation at $1000 \mathrm{~g}$ for $3 \mathrm{~min}$, the lower layer of chloroform extract was carefully removed into a new tube with a Pasteur pipette for testing. Samples $(0.5 \mathrm{ml})$ of the unknown samples of vaginal secretions and culture supernates were treated in the same way.

\section{Cell line}

A monocytic cell line (MonoMac 6), established from peripheral blood of a patient with monoblastic leukaemia [15], was obtained from Gibco (Paisley); $50 \mathrm{ml}$ of the suspension in RPMI medium was diluted with $430 \mathrm{ml}$ of distilled water, supplemented with $6 \mathrm{ml}$ of $1 \mathrm{M} \mathrm{NaoH}, 14 \mathrm{ml}$ of $\mathrm{NaHCO}_{3} 7.5 \%, 5 \mathrm{ml}$ of $200 \mathrm{mM}$ glutamine and $50 \mathrm{ml}$ of fetal bovine serum (FBS) 100\% and propagated at $37^{\circ} \mathrm{C}$ in an atmosphere of $\mathrm{CO}_{2} 5 \%$ in air.

\section{Preparation of human monocytes}

Fresh blood from healthy donors who had not taken antibiotics for 3 months was obtained in anticoagulant (EDTA) and used as a control to the MonoMac 6 cells. This was centrifuged at $400 \mathrm{~g}$ for $30-40 \mathrm{~min}$ at $18-$ $20^{\circ} \mathrm{C}$, over Ficoll-Paque (Ficoll-sodium diatrizoate). Monocytes were removed and washed with balanced salt solution (phosphate-buffered saline) and then suspended in the RPMI medium. The purity of the 
monocytes was $>95 \%$ as determined by trypan blue staining.

\section{Chemotaxis assay}

Chemotactic responses of MonoMac 6 cells were examined by the modified Boyden chamber technique [16], with a 48-well chemotaxis chamber (Neutroprobe, MD, USA). The bottom wells were filled with $26 \mu \mathrm{l}$ of FBS $1 \%$ in RPMI serum-free medium as a positive control, culture supernates with FBS $1 \%$, or vaginal secretions with FBS 1\%. Polycarbonate membranes with $8-\mu \mathrm{m}$ pores (Costar, Cambridge), coated with fibronectin (Sigma) $6.5 \mu \mathrm{g} / \mathrm{ml}$ on both sides, were positioned in the chamber. MonoMac 6 suspensions $\left(45 \mu \mathrm{l} ; 1 \times 10^{6}\right.$ cells $\left./ \mathrm{ml}\right)$ in $\mathrm{RPMI}$ serum-free medium were added to each of the upper wells. The chamber was incubated for $45 \mathrm{~min}$ at $37^{\circ} \mathrm{C}$ in humidified air with $\mathrm{CO}_{2} 5 \%$; the membrane was removed and placed in methanol for $5 \mathrm{~min}$ to fix the cells. The cells were then stained in Harris haematoxylin (BDH, Poole) for $5 \mathrm{~min}$, then placed in tap water for a further $2 \mathrm{~min}$ to define the nucleus. Migration was assessed by counting the number of migrated cells in five microscopic fields/well.

\section{In-vitro study with pure fatty acids}

Succinic, acetic and lactic acids (Sigma) were obtained in highly purified solutions and concentrations were prepared from 0 to $100 \mathrm{mM}$ in RPMI, which were adjusted with sodium hydroxide to $\mathrm{pH} 7.0$ with a Beckman model 3500 digital $\mathrm{pH}$ meter.

Migration tests with MonoMac 6 cells as described above were performed on six occasions with succinic acid, lactic acid and acetic acid. FBS $1 \%$ in RPMI was added to the bottom wells with all concentrations from 1 to $100 \mathrm{~mm}$ of the acids. Human monocytes were also incubated with concentrations of succinic acid to compare them with the MonoMac 6 cell line.

\section{Bacterial strains}

Eleven strains of $G$. vaginalis, which had been stored in liquid nitrogen, were re-cultured on blood agar by incubating at $37^{\circ} \mathrm{C}$ in $\mathrm{CO}_{2} 5 \%$ for $48 \mathrm{~h}$. Ten lyophilised laboratory strains of Prevotella spp., (one strain of $P$. disiens, five of $P$. melaninogenica, one of $P$. oralis and three of $P$. intermedia) were re-cultured by adding $0.5 \mathrm{ml}$ of Fastidious Anaerobic Broth (Lab M, Bury) to the ampoules, mixing and transferring drops on to blood agar plates, and incubating anaerobically at $37^{\circ} \mathrm{C}$ for $48 \mathrm{~h}$. Five lyophilised strains of Mobiluncus spp. (three of $M$. mulieris and two of $M$. curtisii) were similarly re-cultured and incubated anaerobically for 3-4 days. Eleven Lactobacillus strains were also recultured from liquid nitrogen with aerobic incubation on blood agar at $37^{\circ} \mathrm{C}$ for $48 \mathrm{~h}$.

\section{Bacterial culture media}

Cooked Meat Medium (CMM; Difco) was used to grow bacterial strains to measure VFA and NVFA concentrations and to study the effect of culture supernates on cell chemotaxis. To achieve this, samples were streaked on freshly poured blood agar plates and incubated aerobically and anaerobically at $37^{\circ} \mathrm{C}$ for $48 \mathrm{~h}$. Mobiluncus cultures were incubated for 4 days. Colonies were picked from the plates and subcultured into $\mathrm{CMM}$ with $0.1 \mathrm{ml}$ of bacterial suspension $\left(9 \times 10^{8}\right.$ organisms $/ \mathrm{ml}$; MacFarland tube no. 3). CMM broths were incubated anaerobically at $37^{\circ} \mathrm{C}$ for $48 \mathrm{~h}$, and for 4 days in the case of Mobiluncus spp. With Lactobacillus spp. only, CMM broths were incubated aerobically at $37^{\circ} \mathrm{C}$ for $48 \mathrm{~h}$.

\section{Preparation of culture supernates}

Supernates of static cultures were prepared by centrifugation $\left(2000 \mathrm{~g}, 10 \mathrm{~min}, 4^{\circ} \mathrm{C}\right)$, for fatty acid analysis and for the migration test. Culture supernates $(5-\mathrm{ml}$ volumes) were acidified to $\mathrm{pH} 2$ with two drops of $\mathrm{H}_{2} \mathrm{SO}_{4} 50 \%$. The tubes were centrifuged and the clear supernates were removed (once the sample is acidified, the end-products for NVFA and VFA analysis remain stable for several months in the refrigerator). Each strain was cultured in four tubes, so that a mean measurement of acids could be attained. One-ml samples of culture supernates were stored at $-20^{\circ} \mathrm{C}$. As a positive control, FBS $1 \%$ was added to sterile CMM and was loaded in the bottom wells of the chamber.

\section{Collection and processing of clinical samples}

Approval for this study was obtained from the South Sheffield Ethical Committee (ref. SS 98/144). Two well-loaded swabs were taken from the vaginas of 100 non-pregnant women who were attending the Department of Genitourinary Medicine at the Royal Hallamshire Hospital, Sheffield. Each patient had a vaginal examination during which the discharge was assessed. Only those who had not received antibiotic therapy in the preceding 4 weeks were included in the study.

A Gram-stained smear was prepared from one of the swabs in each pair and was examined with a $100 \times$ oilimmersion objective. A diagnosis of BV was made where 'clue cells' and masses of 'gram-variable' bacteria were present and lactobacilli were absent. Specimens were classified as 'normal' when lactobacilli were present and 'clue cells' and 'gram-variable' organisms were not seen. 'Intermediate' grade was recorded when there was a mixed flora containing varying numbers of lactobacilli and 'gram-variable' organisms [17].

The second swab of each pair was eluted in $2 \mathrm{ml}$ of sterile distilled water in a screw-capped 7-ml bottle by gentle shaking for $15 \mathrm{~min}$. The remaining solution was 
then stored at $-20^{\circ} \mathrm{C}$, until tested by gas chromatography analysis and migration tests.

\section{Data analysis}

Increased penetration of cells into or through the filter of a Boyden chamber under the stimulus of a chemical agent is generally taken as indicating chemotactic activity. The chemotactic response of MonoMac 6 cells to FBS $1 \%$ was assessed in a modified Boyden chamber assay. The positive control was FBS $1 \%$ in serum-free RPMI medium, sterile CMM, or distilled water. Negative controls were the above solutions without FBS.

Significant values of cell migration were calculated by the Student's $t$ test. Results were expressed as either the mean number of total cells migrating per three wells in five microscopic fields or as a migration index (MI).

$$
\mathrm{MI}=\frac{\text { Number of cells migrating to test }}{\text { Number of cells migrating to negative control }}
$$

The coefficient of variation was performed on MonoMac 6 cells challenged with different concentrations of pure fatty acids and calculated as:

\section{standard deviation between the means total mean}

The distribution of vaginal fluid and culture supernate NVFA and VFA levels were determined by using the difference of the mean and Student's $t$ test to compare the means for data distributed.

Units used to measure organic acids by gas chromato- graphy were $\mu \mathrm{g} / \mathrm{ml}$ and converted to $\mathrm{mM}$ by dividing by the mol. wt of the acid.

\section{Results}

Gas chromatography levels of fatty acids produced by the organisms tested

Table 1 shows the levels of VFAs and NVFAs produced by 11 strains of $G$. vaginalis, 10 strains of Prevotella spp. (P. disiens, one; P. melaninogenica, five; P. oralis, one; $P$. intermedia, three), five strains of Mobiluncus spp. (M. mulieris, three; M. curtisii, two) and 11 strains of Lactobacillus spp., when grown in CMM and analysed by gas chromatography. Lactobacillus strains produced significantly higher levels of lactic acid, compared with $G$. vaginalis, Prevotella spp., and Mobiluncus spp. Both Prevotella strains and Mobiluncus spp. produced larger amounts of succinic acid than G. vaginalis and Lactobacillus spp. In the case of acetic acid, Prevotella strains produced significantly larger amounts than $G$. vaginalis, Mobiluncus and Lactobacillus spp. Non-significant trace amounts of other NVFAs (pyruvic, oxalacetic, oxalic, methylmalonic, malonic and fumaric acid) were found in all organism supernates. In contrast, other VFAs (propionic, isobutyric, butyric, isovaleric, valeric, isocaproic, caproic and heptanoic acid) were produced in large amounts by Prevotella and Mobiluncus spp. when compared with G. vaginalis and Lactobacillus spp.

\section{Gas chromatography levels of fatty acids in vaginal fluid}

Table 2 shows that high levels of lactic acid were present in normal vaginal fluid and were decreased in

Table 1. Summary of the VFAs and NVFAs generated in the supernates of the cultured organisms associated with BV, and Lactobacillus spp.

\begin{tabular}{|c|c|c|c|c|}
\hline \multirow[b]{2}{*}{ Acid } & \multicolumn{4}{|c|}{ Mean (range) of FAs (mM) in culture supernates of } \\
\hline & $\begin{array}{l}\text { G. vaginalis } \\
\quad(\mathrm{n}=11)\end{array}$ & $\begin{array}{l}\text { Prevotella spp. } \\
\quad(\mathrm{n}=10)\end{array}$ & $\begin{array}{l}\text { Mobiluncus spp } \\
\quad(\mathrm{n}=5)\end{array}$ & $\begin{array}{l}\text { Lactobacillus spp. } \\
\qquad(\mathrm{n}=11)\end{array}$ \\
\hline Lactic acid & $3.43(0-12)$ & $2.45(0-5.9)$ & $1.53(0-7)$ & $17.03(9.2-35.2)$ \\
\hline Succinic acid & $10.2(4-18.8)$ & $19.97(12-32.4)$ & $19.76(16.2-24)$ & $3.3(0-9.2)$ \\
\hline Acetic acid & $6.3(0-15.4)$ & $39.5(1-128)$ & $13.42(0.6-26)$ & $4.3(0-9.2)$ \\
\hline Other NVFAs & $0.5(0-0.5)$ & $1.05(0-4)$ & $3.88(0.04-9.96)$ & $2.2(0-13.5)$ \\
\hline Other VFAs & $0.11(0-0.47)$ & $19.72(0.08-70)$ & $26.48(0-63.4)$ & $1.4(0-10.8)$ \\
\hline
\end{tabular}

Figures in parantheses indicate the range $(\mathrm{mM})$ of acids generated by all the organisms of each strain.

Table 2. Summary of concentrations of lactic, succinic and acetic acid and other NVFAs and VFAs in the vaginal fluid of 100 women with and without BV

\begin{tabular}{|c|c|c|c|c|}
\hline \multirow[b]{2}{*}{ Acid } & \multicolumn{4}{|c|}{ Mean concentration $(\mathrm{mM})$ in vaginal fluid from women with microscopy grading } \\
\hline & Normal $(\mathrm{n}=71)$ & All BV $(n=29)$ & Intermediate $(n=8)$ & BV grade $(n=21)$ \\
\hline Lactic acid & $6.21(0-31.4)$ & $0.714(0-11.1)$ & $2.34(0-11.1)$ & $0.09(0-2)$ \\
\hline Succinic acid & $0.02(0-0.61)$ & $10.13(0.02-21.9)$ & $5.4(0.02-12.8)$ & $11.93(2.36-21.9)$ \\
\hline Acetic acid & $1.54(0-28.4)$ & $18.58(0-65)$ & $15.37(5-36.6)$ & $19.81(0-65)$ \\
\hline Other NVFAs & $0.32(0-3.17)$ & $0.31(0-3.4)$ & $0.27(0-1.11)$ & $0.32(0-3.4)$ \\
\hline Other VFAs & 0 & $0.03(0-1.04)$ & 0 & $0.05(0-1.04)$ \\
\hline
\end{tabular}

Figures in parentheses indicate the range of acid concentrations found in each group of women tested. 
fluids from patients with BV $(\mathrm{p}<0.001)$. A small amount of lactic acid was present in fluids of intermediate-BV grade women $(p>0.01)$. Significantly higher levels of succinic acid were found in fluid from BV patients than in fluid from intermediate-BV grade women. There were low concentrations of succinic acid $(p<0.001)$ in vaginal secretions from normal women. High concentrations of acetic acid were found in all vaginal fluids from BV patients compared with low concentrations seen in normal vaginal fluid $(p<0.001)$. Only trace amounts of other NVFAs (pyruvate, oxalacetic, oxalic, malonic, methylmalonic and fumaric acid) were found in vaginal secretions from normal women and $\mathrm{BV}$-infected women $(\mathrm{p}>0.5)$. Also, trace amounts of other VFAs (propionic, isobutyric, butyric, isovaleric, valeric, isocaproic, caproic and heptanoic) were present in low levels in vaginal secretions from women who were BV grade, but were not present in secretions from normal and intermediate grade women $(\mathrm{p}<0.001)$.

\section{Effect of succinic, acetic and lactic acids on chemotaxis}

Table 3 shows that increasing concentrations of succinic acid resulted in a progressive inhibition of migration of MonoMac 6 cells and that coefficient of variation results indicated that the chemotaxis assay was reproducible. Thus, in all concentrations between 0.5 and $100 \mathrm{mM}$ succinic acid, significant migration and chemokine inhibition was observed $(p<0.001)$ when compared with the positive control. Lactic acid at concentrations of $0.5-100 \mathrm{mM}$ showed an overall mean cell migration, which was not significantly inhibitory to chemotaxis of MonoMac 6 cells $(p>0.5)$. As above, the same concentrations of acetic acid were studied to show inhibition and like succinic acid, migration was significantly different to the positive and negative controls $(\mathrm{p}<0.001)$.

To summarise these results, succinic acid was highly inhibitory to cell migration when compared with lactic acid and acetic acid $(\mathrm{p}<0.001)$. Acetic acid showed significant inhibitory effects on cell migration when compared with the positive and negative $(\mathrm{p}<0.001)$ controls, but this inhibition was not as strong as that seen with succinic acid. In comparison, lactic acid did not show significant inhibition of chemotaxis $(p>0.5)$ (Table 3).

\section{Effect of succinic acid on migration of human monocytes}

Table 4 shows that human monocytes were chemoattracted by FBS $1 \%$, with a high migration effect and a mean of 347 cells seen in the positive control; the negative control showed migration in 39 cells. At $75 \mathrm{~mm}$ succinic acid, human monocytes showed significant inhibition of migration, which increased significantly between 100 and $200 \mathrm{mM}$ succinic acid $(\mathrm{p}<0.001)$. Overall, succinic acid showed similar levels of inhibition with fresh human cells (Table 3) and with the MonoMac 6 cell line (Table 4).

Table 4. Migration of human monocytes from healthy blood, challenged with different concentrations of succinic acid in FBS $1 \%$

\begin{tabular}{lcl}
\hline & \multicolumn{2}{c}{ Mean cell migration } \\
\cline { 2 - 3 } $\begin{array}{l}\text { Concentration of succinic } \\
\text { acid (mM) }\end{array}$ & Total cells* & MI \\
\hline Negative control (RPMI) & 39 & 1 \\
Positive control (FBS 1\%) & 347 & 9 \\
Succinic acid with FBS 1\% & & \\
0.5 & 300 & 7.7 \\
1.0 & 271 & 7 \\
0.5 & 263 & 6.7 \\
10 & 241 & 6.2 \\
25 & 227 & 5.8 \\
50 & 221 & 5.6 \\
75 & 156 & 4 \\
100 & 125 & 3.2 \\
150 & 121 & 3.1 \\
200 & 104 & 2.6 \\
\hline
\end{tabular}

MI, migration index.

* Total cell migration per three wells in five microscopic fields.

Table 3. Mean results of six experiments of migration of MonoMac 6 cells challenged with different concentrations of succinic, acetic and lactic acids

\begin{tabular}{|c|c|c|c|c|c|c|}
\hline \multirow[b]{3}{*}{ Concentration of fatty acid (mM) } & \multicolumn{6}{|c|}{ Mean cell migration } \\
\hline & \multicolumn{3}{|c|}{ Total cells* (coefficient of variation) } & \multicolumn{3}{|c|}{ MI } \\
\hline & Succinic acid & Acetic acid & Lactic acid & Succinic acid & Acetic acid & Lactic acid \\
\hline Negative control (RPMI) & $3.5(0.80)$ & $8(0.3)$ & $6(0.28)$ & 1 & 1 & 1 \\
\hline Positive control (1\% FBS) & $79.3(0.52)$ & $83.6(0.19)$ & $75.3(0.24)$ & 22.65 & 10.45 & 12.55 \\
\hline 0.5 & $33.1(0.49)$ & $58.5(0.23)$ & $55(0.41)$ & 9.45 & 7.31 & 9.16 \\
\hline 1.0 & $30.16(0.43)$ & $59.6(0.23)$ & $54(0.43)$ & 8.61 & 7.45 & 9 \\
\hline 5.0 & $27.16(0.50)$ & $64.3(0.42)$ & $62(0.38)$ & 7.76 & 8.04 & 10.33 \\
\hline 10 & $25.16(0.77)$ & $53.5(0.25)$ & $63(0.32)$ & 7.18 & 6.7 & 10.5 \\
\hline 25 & $21.16(0.80)$ & $54.1(0.2)$ & $65(0.49)$ & 6.04 & 6.8 & 10.8 \\
\hline 50 & $14.5(0.51)$ & $52.6(0.25)$ & $65(0.2)$ & 4.24 & 6.6 & 11.08 \\
\hline 75 & $10.83(0.50)$ & $43.8(0.25)$ & $66.5(0.34)$ & 3.09 & 5.5 & 11.08 \\
\hline 100 & $6.83(0.57)$ & $56.3(0.27)$ & $71.5(0.33)$ & 1.95 & 7.04 & 11.91 \\
\hline
\end{tabular}

MI, migration index.

${ }^{*}$ Total cell migration per three wells in five microscopic fields. 
Effect of bacterial supernates on chemotaxis of MonoMac 6 cells

Table 5 shows the mean results of four migration tests of MonoMac 6 cell lines after incubation with the supernates of BV-associated bacteria compared with positive and negative controls. The negative control contained no activity, but the positive control showed a high mean migration value of 77.7 cells. The supernates of Prevotella and Mobiluncus spp. were significantly more inhibitory than those of lactobacilli and G. vaginalis $(\mathrm{p}>0.001)$. Thus Prevotella and Mobiluncus spp. were strong inhibitors, whereas $G$. vaginalis was less inhibitory.

\section{Effect of vaginal fluid mixed with 1\% FBS on chemotaxis}

The results showed significant attraction of migrating cells by normal vaginal fluid compared with the positive control $(\mathrm{p}<0.001)$. Cell migration was reduced by the vaginal fluids of $\mathrm{BV}$-infected women. There was no significant difference in inhibition of cell migration of fluids from women with intermediate-BV or BV grade $(\mathrm{p}>0.05)$ (Table 6).

\section{Discussion}

It is becoming increasingly clear that microbial interactions in the vaginal ecosystem are complex, during

Table 5. Summary of MonoMac 6 migration tests with culture supernates of $\mathrm{BV}$-associated bacteria and lactobacilli

\begin{tabular}{lcc}
\hline & \multicolumn{2}{c}{ Mean cell migration } \\
\cline { 2 - 3 } Culture supernate & Total cell* & MI \\
\hline Negative control (CMM) & 5 & 1 \\
Positive control (FBS 1\% in CMM) & 77.7 & 15.54 \\
G. vaginalis & 52.23 & 10.45 \\
Prevotella spp. & 37.26 & 7.45 \\
Mobiluncus spp. & 43.68 & 8.74 \\
Lactobacillus strains & 68.25 & 13.65 \\
\hline
\end{tabular}

MI, migration index; CMM, cooked meat medium.

*Total cell migration per three wells in five microscopic fields.

Table 6. Summary of the MonoMac 6 migration test results with vaginal fluids from women with and without BV

\begin{tabular}{lcc}
\hline & \multicolumn{2}{c}{ Mean cell migration } \\
\cline { 2 - 3 } Source of vaginal fluid & Total cells* & MI \\
\hline Negative control (distilled water) & 13.09 & 1 \\
Positive control (FBS 1\% in & 115.5 & 8.82 \\
distilled water) & & \\
Normal grade & 145.87 & 11.14 \\
All BV grades (BV and & 27.76 & 2.12 \\
intermediate) & 34.12 & 2.6 \\
Intermediate grade & 25.33 & 1.9 \\
BV grade &
\end{tabular}

MI, migration index.

${ }^{*}$ Total cell migration per three wells in five microscopic fields. both health and disease. Pathogenic synergic mixtures of anaerobic and aerobic bacteria are commonly implicated in various infections. BV infections are almost always polymicrobial, but the critical role played by the various components of the mixed flora is still not fully understood. Bacterial synergy has been defined as the co-operative interaction of two or more bacterial species that produce a result not achieved by the individual bacteria acting alone [9]. Mackowiak has suggested that one bacterial species may enhance the survival of its partner(s) in the bacterial mixture by providing growth factors, improving the local environment, inhibiting host defence mechanisms, or sharing virulence factors [10].

For organisms to induce pyogenic infections, or any infection for that matter, they must first avoid phagocytosis or intracellular killing by white blood cells. Another mechanism of establishing infection, especially in BV, would be to avoid early contact with the neutrophil PMNLs by inhibiting chemotaxis of monocytes and neutrophils long enough to allow sufficient growth of associated organisms, to eventually overwhelm the phagocytes and establish infection. One excellent candidate for an inhibitory factor is the shortchain fatty acid (SCFA), succinic acid [13].

The in-vitro investigations in the present study demonstrated that when MonoMac 6 cells were incubated with different concentrations of succinic acid, the latter reduced the ability of the cells to respond to chemotactic stimuli and this inhibited cell migration. Whilst acetic acid did inhibit cell migration at different concentrations, it was not as effective as succinic acid. As both these acids are present in vaginal fluid in BV infection, they may react together to inhibit chemotaxis. Interestingly, lactic acid, which is present in high concentrations in the vaginal fluid of normal women, did not show any inhibition of cell migration. The results obtained with human monocytes showed highly active migration by FBS when compared with MonoMac 6 cells, and succinic acid caused inhibition of chemotaxis of both fresh human monocytes and MonoMac 6 cells.

The microbial flora is reputed to be a source of organic acids, which was previously discovered by gas-liquid chromatography. Detection of these acids has led to the development of a laboratory test which uses measurement of the relative levels of succinate and lactate in the vaginal fluid of women with vaginosis [18]. Therefore, it was possible to test chemotactic inhibition by the culture supernates of aerobic and anaerobic organisms grown in cooked meat medium. The conditions of the chromatographic assays used in this work gave good resolution for all the acids. In the present study, acid produced at high mean concentrations by Prevotella and Mobiluncus spp. included acetic (40 and $13 \mathrm{mM})$, succinic (19.97 and $19.76 \mathrm{mM})$ and VFAs (20 and $26.48 \mathrm{~mm}$ ), respectively. Further- 
more, culture supernates of $G$. vaginalis contained mean concentrations of $10.2 \mathrm{mM}$ succinic acid and $6.3 \mathrm{mM}$ acetic acid, but these acids were only present in trace amounts in supernates of Lactobacillus strains. In contrast, Lactobacillus strains produced a high mean concentration of lactic acid $(17.08 \mathrm{mM})$ in culture supernates, but only low levels of this acid were found in culture supernates of BV-associated organisms.

Acetic and succinic acids are the primary end-products of the growth of anaerobic organisms. There are reports [19] indicating that a wide variety of substances which are found in growth media are antichemotactic, or have a high capacity to induce chemotaxis. Of the organisms tested in the present study, the supernates of Prevotella and Mobiluncus spp. that contained high concentrations of succinic and acetic acids showed significant inhibition of cell migration. However, the facultative anaerobe $G$. vaginalis also showed inhibition of cell migration, but to a lesser degree, and Lactobacillus spp. did not inhibit cell migration.

It seems possible that Prevotella and Mobiluncus spp. associated with BV avoid early contact with PMNL by inhibiting chemotaxis for long enough to allow themselves and other organisms to grow. Therefore, BV-associated bacteria can eventually overwhelm phagocytosis and establish infection. The present study clearly showed that Prevotella and Mobiluncus spp. and $G$. vaginalis were capable of inhibiting chemotaxis of MonoMac 6 cells in vitro.

Gas chromatographic analysis showed that larger amounts of characteristic organic acid metabolites were present in vaginal fluid from women with BV than in normal women. The succinic and acetic acid products of anaerobic metabolism can be used clinically as markers for the presence of anaerobes in BV infection. The concentrations of these fatty acids in various infected fluids have been measured and correlated with the presence of various anaerobic species by calculating a succinate:lactate ratio [2]. Previous investigations in this department [20] showed that in the vaginal secretions of women with $\mathrm{BV}$, mean acetic and succinic acid levels were 6270 and $1289 \mu \mathrm{g} / \mathrm{ml}$ (103 and $4.8 \mathrm{mM})$, respectively; the lactic acid concentration was $1791 \mu \mathrm{g} / \mathrm{ml}(19.9 \mathrm{mM})$. After successful treatment with metronidazole, the levels of acetic and succinic acids were reduced to 3665 and $86 \mu \mathrm{g} / \mathrm{ml}$ (61 and $0.32 \mathrm{mM}$ ) respectively. Lactic acid was raised to $7857 \mu \mathrm{g} / \mathrm{ml}(87 \mathrm{mM})$. These findings were confirmed by another group of workers [21], who found succinate:lactate ratios to be greater among women with bacterial vaginosis before treatment than after treatment with metronidazole. In the present study, vaginal fluids from BV-infected women had highly significant mean levels of acetic and succinic acids (up to 18.58 and $10.13 \mathrm{~mm}$, respectively). Moreover, antichemotactic activity was found in the in-vivo study of all vaginal secretions of women infected with $\mathrm{BV}$ in which they inhibited chemotaxis of MonoMac 6 cells.

Succinic acid may represent at least one leukotoxic virulence factor produced by anaerobic BV-associated organisms that are present in the vaginal fluid. The presence of succinic acid and acetic acid in vitro in culture supernates, and in vaginal fluid in vivo may help to explain some of the findings as to why no pus cells are present in vaginal secretions during BV infection. These studies have clearly demonstrated that certain organic acids, produced by the bacteria associated with BV, profoundly impaired chemotaxis.

It is most likely that synergic mechanisms play a role in BV infection. One is based on the anaerobic organisms such as Prevotella and Mobiluncus associated with $\mathrm{BV}$, which elaborate various metabolites, such as succinic acid and acetic acid. Therefore, they might be important virulence factors that may alter the binding of a chemotactic factor to the PMNL surface. These virulence factors may be especially important in inhibiting the chemotaxis of PMNLs, and in the pathogenesis of infectious disease, and allow other organisms which do not produce those acids to grow and contribute to infection.

We gratefully acknowledge the co-operation of Dr G. R. Kinghorn and staff of the Department of Genitourinary Medicine at the Royal Hallamshire Hospital, Sheffield, for their help in obtaining the clinical samples. We would also thank Dr Ali A. Selman for his help and instruction with the cell migration technique.

\section{References}

1. Gardner HL, Dukes CD. Haemophilus vaginalis vaginitis. A newly defined specific infection previously classified 'nonspecific' vaginitis. Am J Obstet Gynecol 1955; 69: 962-976.

2. Spiegel CA, Amsel R, Eschenbach D, Schoenknecht F, Holmes KK. Anaerobic bacteria in non-specific vaginitis. $N$ Engl $J$ Med 1980; 303: 601-607.

3. Winefield AD, Murphy SA. Bacterial vaginosis: a review. Clin Excell Nurse Pract 1998; 2: 212-217.

4. Oppenheim JJ, Zachariae COC, Mukaida N, Matsushima K. Properties of the novel proinflammatory supergene "intercrine" cytokine family. Annu Rev Immunol 1991; 9: 617-648.

5. Taub DD, Oppenheim JJ. Chemokines, inflammation and the immune system. Ther Immunol 1994; 1: 229-246.

6. Duerden BI. Virulence factors in anaerobes. Clin Infect Dis 1994; 18 Suppl 4: S253-S259.

7. Pybus U, Onderdonk AB. A commensal symbiosis between Prevotella bivia and Peptostreptococcus anaerobius involves amino acids: potential significance to the pathogenesis of bacterial vaginosis. FEMS Immunol Med Microbiol 1998; 22: $317-327$.

8. Brook I, Hunter V, Walker RI. Synergistic effect of Bacteroides, Clostridium, Fusobacterium, anaerobic cocci, and aerobic bacteria on mortality and induction of subcutaneous abscesses in mice. J Infect Dis 1984; 149: 924-928.

9. Mikamo H, Kawazoe K, Izumi K, Watanabe K, Ueno K, Tamaya T. Studies on the pathogenicity of anaerobes, especially Prevotella bivia, in a rat pyometra model. Infect Dis Obstet Gynecol 1998; 6: 61-65.

10. Mackowiak PA. Microbial synergism in human infections. (pt 2) $N$ Engl J Med 1978; 298: 83-87.

11. Brook I. The role of encapsulated anaerobic bacteria in synergistic infections. FEMS Microbiol Rev 1994; 13: 65-74.

12. Hofstad T. Pathogenicity of anaerobic gram-negative rods: possible mechanisms. Rev Infect Dis 1984; 6: 189-199. 
13. Namavar F, Verweij AMJJ, Bal M, van Steenbergen TJM, de Graaff J, MacLaren DM. Effect of anaerobic bacteria on killing of Proteus mirabilis by human polymorphonuclear leukocytes. Infect Immun 1983; 40: 930-935.

14. Rotstein OD, Vittorini T, Kao J, McBurney MI, Nasmith PE, Grinstein S. A soluble Bacteroides by-product impairs phagocytic killing of Escherichia coli by neutrophils. Infect Immun 1989; 57: 745-753.

15. Ziegler-Heitbrock HWL, Thiel E, Fütterer A, Herzog V, Wirtz A, Riethmüller G. Establishment of a human cell line (Mono Mac 6) with characteristics of mature monocytes. Int $J$ Cancer 1988; 41: 456-461.

16. Wang MJ, Taraboletti G, Matsushima K, Van Damme J, Mantovani A. Induction of haptotactic migration of melanoma cells by neutrophil activating protein/interleukin-8. Biochem Biophys Res Comm 1990; 169: 165-170.
17. Nugent RP, Krohn MA, Hillier SL. Reliability of diagnosing bacterial vaginosis is improved by a standardized method of gram stain interpretation. $J$ Clin Microbiol 1991; 29: 297-301.

18. Hillier SL. Diagnostic microbiology of bacterial vaginosis. Am J Obstet Gynecol 1993; 169: 455-459.

19. Wexler DE, Nelson RD, Cleary PP. Human neutrophil chemotactic response to group A streptococci: bacteriamediated interference with complement-derived chemotactic factors. Infect Immun 1983; 39: 239-249.

20. Jones BM. Bacterial vaginosis. PhD thesis, 1990, University of Sheffield.

21. Stanek R, Gain RE, Glover DD, Larsen B. High performance ion exclusion chromatographic characterisation of the vaginal organic acids in women with bacterial vaginosis. Biomed Chromatogr 1992; 6: 231-235. 